\title{
Formação de professores: a política e as diretrizes curriculares*
}

\author{
Maria Beatriz Luce \\ entrevistada por Fernanda Borges de Andrade
}

Fernanda Andrade: Em relação à formação de professores hoje, quais são as demandas e desafios curriculares que a senhora gostaria de comentar?

Maria Beatriz Luce: Considero importante situarmos a discussão das diretrizes curriculares de formação de professores, recentemente atualizadas e que agora estão sendo implantadas no Brasil, no contexto mais amplo das políticas educacionais. A formação de professores para a educação básica vem sendo, e precisa ser, tema central de todos os lugares e de todos os atores do sistema educacional - não apenas nas universidades, mas também nas escolas, contando com as secretarias e os conselhos municipais e estaduais de educação, com o Ministério da Educação (MEC) e o Conselho Nacional de Educação (CNE), justamente na mesma configuração federativa e participativa em que devem ser formuladas as políticas para todos os profissionais da educação. Felizmente, desde a Constituição de 1988, tivemos o fortalecimento da organização das redes municipais - com a instituição dos sistemas municipais de educação, ao lado dos estaduais - e também o crescimento da atuação do MEC e do CNE em relação à educação básica.

\footnotetext{
* Entrevista realizada via Skype, nos dias 15 e 16 de junho de 2016. Na impossibilidade de transcrever integralmente 10 horas de conversa gravada, cuidamos de assegurar aqui seu teor e procuramos trazer os aspectos mais marcantes sobre a concepção que perpassa as Diretrizes Curriculares de Formação de Professores na atualidade e sobre o Pibid como política de formação docente.
} 
A formação de professores tem de ser tratada - em um espaço e tempo de diálogo e de articulação, de interatuação entre a educação superior e a educação básica - como uma questão complexa e uma política pública em movimento, por excelência federativa, ou seja, própria do Sistema Nacional de Educação (SNE), constituída e constituinte nesse/desse sistema. Assim, situamos a definição e a concretização da formação de professores no cerne da discussão sobre a política nacional curricular da educação básica, porque a política de currículo e a política de formação são estruturantes da qualidade da educação. Uma é conteúdo e, de certa forma, estratégia da outra. Ao estudar, planejar e avaliar o currículo, nos formamos, pesquisando o campo da educação escolar, com suas múltiplas interfaces e perspectivas, antes e durante nossa atuação como profissionais.

Vivenciamos um momento de muita mobilização nas cidades no âmbito dos governos municipais e estaduais, mas especialmente em relação às políticas do governo federal, com movimentos de estudantes e professores, nas universidades e nas escolas, preocupados com a anunciada desaceleração dos investimentos que têm sido feitos em formação de professores, com a discussão da política nacional curricular e com a descontinuidade dos avanços que foram conquistados nos últimos anos.

A desaceleração de investimentos, que está proposta na PEC nº 241 ou PEC $n^{\circ}$ 55/2016, se for aprovada pelo Congresso Nacional, atingirá tanto a produção material quanto a produção intelectual da Nação. Incidirá diretamente sobre a manutenção e o desenvolvimento dos sistemas municipais, estaduais e federal de ensino. Limitará a política de valorização dos profissionais da educação básica e da educação superior, não apenas quanto à remuneração e condições de trabalho melhores, com carreiras mais atraentes, mas também quanto à viabilidade de melhorarmos a qualidade dos cursos de formação inicial e continuada dos professores e dos técnico-administrativos de escolas e universidades. Limitará, ainda, a adoção e a inovação das/nas tecnologias educacionais, o Programa Nacional do Livro Didático, o Programa de Bibliotecas Escolares, os projetos de tecnologias digitais para a educação, incluindo a TV-Escola, os objetos de aprendizagem, as plataformas digitais e os equipamentos que estão chegando às salas de aula, aos professores e aos estudantes.

A infraestrutura escolar, que ainda não é suficiente nem adequada, na maior parte das localidades, também já está sofrendo em virtude da falta de investimentos e de perspectivas. O acesso e continuidade nos estudos para todos com melhoria da qualidade do ensino e combate às desigualdades regionais e intraescolares, conforme o Plano Nacional de Educação (20142020), estão ameaçados. Pretendo, dessa forma, reconhecer a política educacional como uma problemática crucial, que se insere no cenário 
da crise econômica, política, social e estrutural que estamos vivenciando. Esta, por sua natureza, é uma crise ética, que envolve a discussão, ou melhor, um embate de valores na nossa sociedade, porque diz respeito à justiça e equidade, à qualidade da educação, quando se decide sobre que educação, para quem, com que meios. Qualidade da educação é um termo que abriga vários pontos de vista, assim como a formação inicial e continuada de professores para a educação básica. Daí porque a política de formação e a política curricular são tão disputadas.

Na concepção de SNE, articulamos os direitos de cidadania ao projeto de democracia do País, como direito à educação, ao trabalho, à informação e à discussão das relações de poder nas decisões sobre que educação queremos. Desejamos construir o SNE com espaços e tempos institucionalizados para discutir sobre o conteúdo, os métodos de ensino e sobre os resultados das avaliações, que têm sido escrutinados e comparados frequentemente, inclusive com outros países postos em contexto. Devem ser considerados: o direito à educação, o dever do Estado e da família, a gestão pública e a iniciativa privada no setor. Porém, na diversidade de fatos e argumentos a respeito dessas decisões, entre problemas e soluções para a educação das pessoas, para a escola e a universidade, não podemos deixar de perceber que o que está em disputa é o projeto político-educacional do nosso País. Então, é necessário atentar para a condição estrutural de desigualdades regionais, assim como as que ocorrem dentro dos próprios estados federados, dos municípios, de cada cidade e até entre as escolas de um mesmo bairro.

A desigualdade na educação básica se compõe, condicionada e condicionante, na desigualdade das condições de formação dos professores na educação superior. Não me refiro aqui apenas às desigualdades de titulação dos professores, mas também, e principalmente, às desigualdades escondidas na formalidade de uma titulação. Temos progredido no percentual de docentes titulados, mas temos muitas dificuldades de ter professores com licenciatura em áreas de conhecimento adequadas às necessidades das escolas e que sejam condizentes com o projeto curricular adotado no plano nacional e nos sistemas estaduais e municipais de educação. É conhecida a deficiência na oferta de licenciaturas em matemática, línguas estrangeiras e ciências, porque estas têm mobilizado uma parcela importante dos principais cientistas e dos professores dessas matérias no País. Contudo, temos deficiência em outras áreas igualmente basilares, que não têm tido, ainda, a mesma divulgação e consideração, como as humanidades, as artes e os esportes, nas suas diversas expressões, que são extremamente importantes para a formação cultural e para o desenvolvimento das pessoas - inclusive para a aprendizagem da matemática e das ciências. 
Fernanda Andrade: Artes acaba sendo um conteúdo que fica meio perdido na escola, que é desprestigiado.

Maria Beatriz Luce: Temos pouca oferta de licenciaturas em artes, pouca diversidade de artes nas escolas. Mas o fato de termos, por exemplo, mais abundantemente cursos de letras e de história, assim como de pedagogia, não pode nos tranquilizar porque neles há seríssimos problemas de qualidade. Somos também um país deficiente de professores na área da geografia, sociologia e filosofia. A formação de professores, no Brasil, nasceu nas faculdades de filosofia, ciências e letras, mas a filosofia e as ciências não têm o devido reconhecimento no currículo da educação básica e as letras são reduzidas. Carecemos de planejamento da formação de professores, e nos damos conta de que a forma fragmentada que domina os nossos currículos, tanto nas universidades quanto na educação básica, é inadequada. No mundo inteiro, tornou-se tema contemporâneo a interdisciplinaridade e buscam-se modelos e estratégias curriculares para praticá-la. Se não for praticada na educação básica, como realizá-la na educação superior? E se não for praticada nas licenciaturas, como formar professores com a concepção que o mundo requer: múltiplos olhares, olhares cruzados e trabalhos coletivos entre pessoas com diferentes formações em diferentes disciplinas, em diferentes perspectivas?

As novas Diretrizes Curriculares Nacionais da Educação Básica e as da Formação de Professores - inicial e continuada - já apontam para o ensino por áreas mais amplas de conhecimento, articulando disciplinas. Felizmente, as universidades que iniciaram essas novas licenciaturas por áreas, com projetos curriculares inovadores em conteúdo e em metodologias, com aprofundamento de estudos em uma ou outra disciplina, têm tido boa acolhida. Novas universidades federais do Rio Grande do Sul, Minas Gerais e São Paulo têm sido muito ativas nessa discussão, que teve início há mais de dez anos. Durante os últimos anos, o MEC, por meio da Sesu, ${ }^{1}$ da SEB ${ }^{2}$ e da Setec $^{3}$; o CNE, por meio da Comissão Bicameral de Formação de Professores, e a Coordenação de Aperfeiçoamento de Pessoal de Nível Superior (Capes) promoveram discussões em grupo de estudo que já aprontou uma proposta de orientação curricular para essas licenciaturas por área. Parece-me importante que o CNE venha a considerá-la para que possam se multiplicar tais cursos.

Fernanda Andrade: A senhora acredita que essas licenciaturas resolveriam um pouco a falta de professores, o interesse dos alunos pela licenciatura e o desprestígio profissional?

\footnotetext{
${ }^{1}$ Secretaria de Educação Superior.

2 Secretaria de Educação Básica.

${ }^{3}$ Secretaria de Educação Profissional e Tecnológica.
} 
Maria Beatriz Luce: Penso que é importante formar pessoas com visão mais abrangente, que consigam transitar e articular conhecimentos disciplinares e tratar da complexidade dos fenômenos da natureza, da sociedade e das pessoas. Mas, esclareço que não estou propondo a extinção do ensino disciplinar; será igualmente importante manter os profissionais com conhecimentos mais aprofundados em disciplinas e/ou questões mais específicas nos sistemas de ensino e em escolas.

É preciso inovar, mas com cautela. Aliás, até que um razoável contingente de professores formados por área seja incorporado pelos concursos e projetos político-pedagógicos da educação básica, podemos antecipar que tanto estes como os professores atualmente em exercício, formados em licenciaturas disciplinares, enfrentarão um grande desafio que é o trabalho em grupo, o planejamento curricular e didático coletivo. Sabemos que os professores iniciantes demoram um certo tempo para conseguir mostrar aos seus colegas mais antigos a qualidade de sua nova formação. Eles precisam ser habilidosos nesse sentido. Por isso, é muito importante que todas as licenciaturas, por área ou por disciplinas tradicionais, estejam em condições de dialogar e apoiar as inovações curriculares feitas nas escolas e universidades.

O triângulo virtuoso de ensino, pesquisa e extensão é a base da excelência na formação inicial e continuada de professores. Programas que atuem na rede escolar, forjados em parceria da coordenação pedagógica das escolas e das secretarias de educação com as universidades, são fundamentais à constituição do campo de pesquisa e de prática para a formação inicial e a continuada. A universidade nas escolas, as escolas na universidade, licenciandos e licenciados trabalhando juntos com os professorespesquisadores das licenciaturas e da pós-graduação em educação e em ensino, parecem-me a melhor maneira pela qual tem se avançado na construção de conhecimentos sobre a educação básica e a formação de professores.

Fernanda Andrade: Nesse ponto, o Programa Institucional de Bolsa de Iniciação à Docência (Pibid) foi um avanço, porque só o estágio não tem se mostrado suficiente.

Maria Beatriz Luce: O Pibid foi lançado como um programa especial e se ele é um sucesso, como dita a avaliação de professores e estudantes universitários e a das escolas, seria hora de alçar seus processos de trabalho e os recursos que os possibilitam à condição de institucionalização, isto é, da excepcionalidade à regularidade nas práticas e nos orçamentos das escolas e das universidades.

Os protagonistas dessa inovação foram pessoas com ousadia e capacidade de colocar coisas novas em marcha. O desafio, agora, é disseminar, 
incorporar a concepção e os meios do Pibid. Há que atualizar os conhecimentos e as práticas da formação de professores quanto a currículo, conteúdos, métodos da docência e tecnologias adequadas para o trabalho nas licenciaturas e para a transposição didática às escolas de educação básica. Portanto, que tenhamos o Pibid como horizonte e lutemos para que ele se concretize até que seja plenamente institucionalizado, não mais como um projeto especial temporário e pontual, limitado em vagas para licenciandos e alguns de seus professores, limitado a algumas escolas de educação básica.

Esse não é um desafio pequeno, mas já temos a janela aberta e o cenário composto para isso: as novas Diretrizes Curriculares de Formação Inicial e Continuada de Professores, publicadas em 2015, são resultantes de estudos e discussões intensas - aprofundadas e abrangentes nas universidades que foram sistematizadas pelo CNE, justamente na Comissão Bicameral de Professores, ou seja, entre a Câmara de Educação Básica e a Câmara de Educação Superior. Falo com muita convicção sobre a qualidade dessas diretrizes, porque atendem e incorporam a concepção e as experiências do Pibid e de muitos outros bons projetos de muitos lugares e vertentes.

Em suma, as diretrizes têm na base a concepção de que a universidade precisa estar na/com a educação básica; que os professores deste nível de ensino precisam ter condições de voltar à universidade com certa frequência; e que as escolas disponham de uma organização em que a formação continuada dos profissionais esteja em sua agenda diária, semanal e anual e promovam discussões e aprendizagens interdisciplinares e interinstitucionais para introduzir projetos, programas e atividades inovadoras no próprio currículo. Assim, tendo em vista essa concepção, escolas, secretarias de educação e universidades devem atuar juntas em ações de promoção da qualidade da educação básica.

Fernanda Andrade: A gente vê, atualmente, uma desconfiguração do Pibid que acaba restringindo ainda mais o programa a quase um reforço escolar nas áreas de alfabetização e matemática. Isso é preocupante.

Maria Beatriz Luce: Mais recentemente, têm sido tempos difíceis para o programa; mas a mobilização de resistência e a reinvenção em universidades e escolas têm potencial exemplar. Fico com esperança de que certas propostas, como a de redução das áreas e atividades de atuação no currículo escolar e nas universidades, não prosperem. O valor do Pibid é exatamente outra concepção de conhecimento, de projeto político-pedagógico; é isto que está em disputa. Tenho a impressão de que algumas das medidas anunciadas, que alteram a configuração do Pibid, foram mais para testar uma força política, sem a oportunidade da reflexão ampla sobre os seus fundamentos 
e as avaliações já feitas. Até porque tais críticas não foram pronunciadas antes ou noutros lugares, trata-se de medidas pontuais e temporárias, tomadas apenas para um ajuste orçamentário. Como não reconhecer a importância de manter e até de ampliar as atividades de formação como o Pibid? Nesse quadro, uma oportunidade e um grande desafio: distinguir nossas conquistas no Pibid, a natureza do conteúdo e a forma de organização do trabalho nas licenciaturas e nas escolas, e, igualmente, ampliar o que valorizamos e aprendemos como educação de qualidade.

No que diz respeito a bolsas de estudo, eu creio ser esse um ponto importante para nossas discussões, nas reivindicações para o momento presente e para os recursos do futuro, visando à transposição da forma de trabalho do Pibid para o projeto pedagógico dos cursos de licenciatura e das escolas. Este é o ano (2016) no qual temos de propor um novo projeto pedagógico para os cursos de licenciatura. Não podemos fazer das novas diretrizes curriculares nacionais remendos, como simplesmente aumentar cargas horárias deste ou daquele componente, sem rever os objetivos, os princípios e a estrutura do currículo, as áreas e disciplinas, as sequências e consequências, os tempos, lugares, práticas e sujeitos da formação docente.

Fernanda Andrade: Quando fala de bolsas, poderia nos esclarecer melhor o que pensa?

Maria Beatriz Luce: O Pibid foi concebido com as melhores bases conceituais sobre docência e inovação curricular para as licenciaturas e para a formação continuada nas escolas. Considero serem essas duas qualidades de grande importância para a formação dos futuros professores e daqueles que estão em exercício em sala de aula. Numa época de crescimento do orçamento na área da educação, foi possível começar o Pibid e vários outros programas de melhoria da qualidade da educação básica e da formação docente. Neste momento, em que a política oficial quer limitar as despesas primárias, mas não as de retribuição ao setor financeiro, impulsiona-nos a continuar lutando por um orçamento justo e forte na área de educação. Por isso defendo que os valores para a melhoria da qualidade da formação docente precisam ser mantidos e até aumentados, e que as formas de apropriação desse orçamento possam também ser repensadas, por exemplo, com destaque específico na matriz orçamentária e que sejam essas práticas e o respectivo orçamento institucionalizados, com sentido de continuidade e não apenas de um programa especial temporário.

Sabemos que as bolsas do Pibid são importantes para que muitos dos nossos licenciandos possam dedicar mais tempo aos estudos, incluindo nestes as atividades do programa, e não tenham que buscar seu sustento 
em trabalho fora da universidade - pelo menos parcialmente, porque os valores dessas bolsas não são de manutenção integral. Alguns bolsistas têm o apoio complementar da família, outros da assistência estudantil. Por isso foi importante que o Pibid surgisse e é importante que seja mantido oferecendo bolsas para a iniciação à docência, como já ocorria na tradicional iniciação científica. Todavia, penso que a ampliação das práticas do Pibid para todos os estudantes de licenciatura - maior relação entre pesquisa, ensino e extensão na educação básica, maior intensidade de contatos e práticas formativas nas escolas públicas - requer a destinação de recursos compatíveis com tais atividades de estudantes, professores e técnicoadministrativos, mas não necessariamente bolsas para todos. Na mesma perspectiva, estão as bolsas para os professores supervisores, que acolhem e articulam o Pibid nas escolas. Para estes, as bolsas foram um incentivo atraente para um trabalho novo e exigente, mas também por causa da fraca remuneração do magistério.

Nossa luta principal precisa ser por uma remuneração compatível com o nível profissional e pela institucionalização da formação continuada, de pesquisas e de extensão nas escolas. Isto é por demais importante: jamais descuidarmos, ao falarmos de formação de professores, de que a formação inicial está intimamente ligada à formação continuada, mutuamente condicionadas e condicionantes, bem como às condições de trabalho nas escolas, ao desenho e condições de implantação das suas carreiras e aos incentivos que estas dão à atividade de inovação e formação continuada, inclusive à progressiva titulação.

Precisamos garantir tempo para o planejamento e para a formação continuada na escola por período, cada ano letivo e cada fase da carreira, porque os professores também podem e devem realizar sua formação continuada em períodos de recesso dos alunos, ou seja, aqueles que não sejam de férias ou dias letivos. Assim nos vejo buscando uma política de valorização do magistério: carreira, remuneração e condições de trabalho juntas com a formação inicial e continuada - integradas e estruturantes da qualidade da educação.

Falando ainda das bolsas, é importante lembrar que também temos no Pibid bolsas para os professores universitários que se dedicam a projetos inovadores das licenciaturas, no campo da docência, similares ao estímulo à produção científica. Por isso eu disse que é preciso olhar com muito cuidado e discutir a qualidade da formação docente; e o Pibid pode nos ajudar a decidir sobre o que institucionalizar no projeto curricular das licenciaturas. É necessário vermos exatamente quais as condições de trabalho que, na universidade e nas escolas, são importantes para todos e não apenas para alguns. Propugnamos, além do programa especial, por investimento 
e alocação orçamentária compatível com um projeto institucionalizado para a formação de professores com qualidade; não mercantilizar o compromisso com a inovação curricular e a qualidade acadêmica por uma remuneração temporária e pontual.

Com isso quero dizer que, para além da questão do dinheiro - necessário e insubstituível -, nós precisamos de outras estratégias e recursos para a institucionalização das formas de trabalhar interdisciplinarmente, e também nas e com as escolas de educação básica. Valorizar esse tipo de atividade na carreira do magistério superior, na avaliação dos professores universitários, na progressão funcional ou de carreira, na distribuição dos encargos, enfim, em todas as formas, porque os efeitos de uma política de incentivo à produção científica que nosso País vem adotando têm sido considerados positivos e visíveis. Refiro-me à política de incentivos à produção científica por programas como os da Capes e do Conselho Nacional de Desenvolvimento Científico e Tecnológico (CNPq).

É preciso também valorizar a dedicação à docência e à extensão universitária; porém, com cuidado para evitarmos os problemas expressos no produtivismo acadêmico. Como reconhecer a produção de conhecimento e de recursos didáticos para a educação básica, como o Qualis? E como institucionalizar um ambiente organizacional mais adequado para a formação docente? Há muito o que fazer ao nosso alcance dentro da própria universidade, em cada curso, cada departamento. Como as formas de organização das universidades são cada vez mais variadas, felizmente, podemos construir com mais autonomia e sintonia com os tempos e espaços do campo de atuação das licenciaturas, que é a educação básica. Hoje já temos universidades sem departamentos, que se organizam em campus ou centros, como unidades acadêmicas maiores e menos disciplinares que as faculdades, escolas e institutos - em centros interdisciplinares, inclusive.

Então, precisamos valorizar essas atividades de trabalho com os alunos das licenciaturas, nas suas práticas, nas suas atividades de observação, nos pequenos e nos grandes estágios de um semestre ou dois de duração, de tempo integral nas escolas. Precisamos dedicar mais a pós-graduação à formação de professores da educação básica. Uma forma em que estou apostando, atualmente, é o mestrado profissional em educação, desenvolvido em parceria com as redes escolares para a formação continuada e cujos mestrandos podem apoiar as licenciaturas no campo de prática.

Que seja também mais valorizada a educação continuada, mas de forma institucionalizada nas escolas e na carreira do professor da educação básica, na distribuição das horas de trabalho e dos encargos dos professores das escolas. Quero enfatizar a importância de o corpo docente das escolas 
públicas dispor de tempo e recursos necessários para a sua formação continuada e para o acolhimento dos estudantes e professores da formação inicial, assim como para a gestão democrática dessa parceria. Que a escola tenha um quadro de pessoal compatível com o seu projeto políticopedagógico, constituído por pessoas que tenham disponibilidade e formação adequada, que sejam valorizadas pela atividade de coordenação pedagógica e de inovação pedagógica, inclusive. Promovendo essa articulação com a universidade, precisamos transitar para um momento de real e profunda mudança no conteúdo e no modo da formação inicial - reformando a concepção e a organização do trabalho nas licenciaturas, atuando junto com as escolas na sua reorganização como um ambiente de trabalho e reconhecendo suas diferentes atividades e formas de trabalho.

Fernanda Andrade: Os profissionais que realizam as atividades não docentes também precisam de formação. Como será feita?

Maria Beatriz Luce: A escola precisa se organizar contando não apenas com professores, mas com um quadro de técnicos de nível médio e superior que seja coadjuvante do trabalho dos professores, atuando na área pedagógica, administrativa e de apoio. Para isso, já temos as novas diretrizes curriculares para formação dos técnicos de nível médio para a área da educação. Inclusive, estamos pensando em cursos de tecnólogos, cursos de gestão da educação para profissionais não docentes.

Os institutos federais estão especialmente trabalhando com essa noção, dentro da concepção das novas diretrizes, feitas para atender inclusive uma modificação que havia sido feita há vários anos, quando eu ainda estava na Câmara de Educação Básica do Conselho Nacional de Educação. Aumentamos o catálogo de cursos técnicos para comportar a área da educação, por ser uma área extremamente importante e que requer especialização. Esses cursos podem ser feitos também por escolas técnicas de nível médio, podem contar com apoio conveniado de universidades, mas os considero de grande potencial para as antigas escolas estaduais que ainda tenham corpo docente com formação pedagógica adequada para a formação de pessoas na área de educação. Refiro-me àquelas escolas que antigamente se dedicavamà formação de magistério de nível médio.

Hoje trabalhamos com a formação de professores na educação superior, nas universidades, mas os cursos técnicos, principalmente aqueles que são feitos concomitantemente com o ensino médio e pós-médio, precisam formar pessoas que vão trabalhar na alimentação escolar, nas bibliotecas, na assistência administrativa, na segurança da escola, no apoio técnico e tecnológico aos professores, no cuidado das crianças, principalmente na educação infantil. Com técnicos formados, podem abrir-se novos cargos 
no quadro das escolas e nas carreiras vinculadas às secretarias de educação dos municípios e do estado. Então, é toda uma área que já está bem formulada, na qual vimos trabalhando de longa data, para compor o quadro dos profissionais da educação. Dessa forma, enfatizo: nós temos que renovar e inovar os currículos das licenciaturas, mas também renovar e inovar as nossas formas de relacionamento com as escolas e com as secretarias de educação.

Fernanda Andrade: Como acontece, em nível nacional, o debate sobre a formação de professores?

Maria Beatriz Luce: Desde 2009, tem se estabelecido um ambiente nacional dedicado à discussão, à formulação, ao acompanhamento e à avaliação da política nacional de formação de professores, ${ }^{4}$ que tem uma organização em cada estado com representação das universidades e dos sistemas municipais de ensino, sendo coordenado pela secretaria estadual. É muito importante manter vivo e estar sempre revitalizando esse fórum de discussões substantivas sobre os programas que as secretarias municipais e/ou estaduais mantêm com as universidades para a formação continuada e inicial. Também é importante ali discutirmos os nossos PPCs ${ }^{5}$ das licenciaturas com os órgãos dos sistemas da região, as escolas, os egressos que estão hoje se destacando, e os profissionais que superam as limitações da sua formação inicial, feita por nós, que são bons professores.

Fernanda Andrade: Quais são as deficiências da formação de professores atual?

Maria Beatriz Luce: Mais do que nunca, preocupa-me que os professores das licenciaturas - dentre os quais me incluo -, estão lendo e discutindo pouco sobre a pesquisa produzida sobre docência e formação de professores. Quais são as variáveis, os fatores, as condições em que se formam melhor os professores? Isso vale também para toda a pedagogia universitária, as fragilidades que nós temos de domínio dessa matéria não são menores que as limitações das licenciaturas. Eu me surpreendo, muitas vezes, como nós não usamos argumentos com base em pesquisa, mas nem por isso se pode admitir o trabalho para a formação docente como menor, menos exigente ou menos valorizado do que o da formação científica.

A iniciação à docência tem suas peculiaridades, precisa construir mais sua própria identidade, que não é de natureza diversa ou oposta à iniciação científica. É iniciação "científica" no campo da docência, essa é a noção do

\footnotetext{
${ }^{4}$ Estabelecida no Decreto no 6.755/2009, revogado e atualizado por meio do Decreto no 8.752/2016, que dispõe sobre a Política Nacional de Formação dos Profissionais da Educação Básica. Disponível em: <http://www.planalto.gov.br/ ccivil_03/_Ato2015-2018/2016/Decreto/D8752.htm\#art19>.

${ }^{5}$ Projetos Pedagógicos de Cursos.
} 
Pibid de que falamos. É extremamente importante compreender e fazer com que os nossos cursos de licenciatura não tenham falta de conteúdo, de tempo de estudo e de dedicação sobre a produção científica na área de formação de professores, de organização do trabalho na escola e na universidade, de desenvolvimento e uso das tecnologias. Havendo o abreviamento ou superficialidade desses conhecimentos e das correspondentes práticas, os nossos cursos vão se empobrecendo.

Contamos, ainda, com o problema real de que os nossos alunos das licenciaturas são em vasta maioria trabalhadores que estudam. Isso tem levado a uma cultura de que cursos de licenciatura não sejam de tempo integral ou que possam funcionar em horários e lugares nos quais não se tenha o campo de prática disponível para observações, entrevistas, experimentações, práticas e estágios. Essa problemática da desigualdade econômica incide sobre as condições dos cursos de graduação.

Fernanda Andrade: Temos observado - e as pesquisas têm confirmado -, uma desvalorização das disciplinas pedagógicas nas licenciaturas. Constatei que aqueles que se integram ao Pibid dão mais valor à psicologia, sociologia, filosofia, didática num universo onde, algumas vezes, os próprios professores das disciplinas específicas se acham em vantagem em relação aos das disciplinas pedagógicas. Teria algo a comentar sobre o tema?

Maria Beatriz Luce: Isso acontece, sim, por vários motivos. Os professores das disciplinas básicas e os da formação pedagógica não se conhecem, não dialogam. Eles não podem construir respeito e conhecimento uns sobre a matéria e as práticas dos outros, porque não estão juntos em nenhuma das práticas, em nenhum dos projetos de pesquisa que precisamos ter nas escolas e sobre as escolas.

Em algumas universidades estamos vivendo, nos últimos anos, um fenômeno com o qual eu não consigo me conformar, porque não considero ser essa uma solução para um problema que tem razões, mas nem todas desveladas ou que justificariam a nova situação. É fato que algumas licenciaturas estão sendo criadas sem nascerem junto com a "Faculdade de Educação", setor mais especializado em formação de professores. Há áreas, como matemática e física, entre outras, que estão constituindo licenciaturas em seus institutos, inclusive, fazendo currículos com várias qualidades, já de acordo com as novas diretrizes quanto a mais práticas etc., mas com um corpo docente que não está dialogando com os fundamentos da educação, com a didática geral, com as práticas e os estágios articulados com outras áreas. Professores e licenciados que não se encontram interdisciplinarmente, multidisciplinarmente, estão, assim, fazendo uma formação de professores disciplinar e separada dentro da universidade. Isso está acontecendo e, ao 
invés de articulação e interdisciplinaridade, estamos caminhando para a fragmentação, o isolamento.

Isso não é questão que vá se resolver com bolsa ou com algum programa especial. Precisamos ter uma discussão na própria universidade sobre essas concepções e com as secretarias de educação também, para que essas instituições trabalhem juntas, favorecendo o coletivo multidisciplinar e interdisciplinar nas escolas.

Fernanda Andrade: E sobre os espaços onde podem atuar os alunos das licenciaturas, há previsão nos projetos político-pedagógicos das escolas?

Maria Beatriz Luce: Na universidade e na educação básica, articuladamente, é preciso discutir também a política de currículo, a de materiais e tecnologias educacionais, assim como a política de formação inicial e continuada e a de gestão democrática das escolas e da política educacional.

Incluo, ainda, a política de infraestrutura escolar, porque a arquitetura do prédio e o uso do espaço, inclusive do pátio escolar e de outras dependências, são fundamentais para as atividades de formação de professores. Precisamos de espaços adequados nas escolas para que nossos alunos das licenciaturas estejam nas salas de aula, nos laboratórios e nas bibliotecas e, precisamos, ao mesmo tempo, rever permanentemente a nossa política de avaliação - a avaliação da educação básica e a da universidade, no sentido de avaliações institucionais sobre o projeto pedagógico, e a avaliação da concepção e da implementação do projeto pedagógico numa perspectiva institucional.

Tudo isso depende de uma adequada política de financiamento, e, no momento, há uma crise econômica e orçamentária no bojo da crise ética e política. Não é admissível a severa ameaça a um dos últimos bastiões que temos, que é a vinculação orçamentária da educação - uma conquista do início dos anos 80, ainda na transição democrática, com a Emenda Calmon, consagrada na Constituinte de 1988. Está ameaçada! Então, nós precisamos fazer essa discussão em contexto.

Mais do que tudo, na formação de professores é preciso considerar as diretrizes curriculares nacionais, estaduais e municipais da educação básica e as diretrizes de formação, além das necessidades de pessoal, infraestrutura e materiais para a educação pública de qualidade. Estávamos discutindo-as e não podemos esmorecer nem nos atrasar com outra Base Nacional Comum Curricular da Educação Básica, nem com o que temos chamado de "base comum nacional das licenciaturas". Essa discussão, que já vem de décadas, também precisa convergir com as demais políticas. 
Fernanda Andrade: Os mestrados profissionais podem ser vistos como formação continuada?

Maria Beatriz Luce: No meu entender, os mestrados profissionais em educação e ensino são uma oportunidade de formação continuada de professores. Quando têm uma concepção realmente adequada desse curso, os mestrandos são profissionais da educação - em efetivo exercício ou licenciados - com condições de participarem de um coletivo de orientação que, desde o primeiro dia de estudos, ocupa-se com um eixo de formação que é o projeto de diagnóstico das condições da instituição onde trabalham. Esse diagnóstico vai resultar na elaboração de um projeto de intervenção, ou um projeto de pesquisa-ação, que tem como culminância do mestrado um relatório dessa intervenção, dessa pesquisa-ação, realizada no lugar de trabalho, nas horas de trabalho, durante o mestrado. Isso, para mim, é extremamente auspicioso.

Fernanda Andrade: O curso de pedagogia tem sido considerado muito abrangente, não formando adequadamente o professor nem o supervisor pedagógico. O que pensa sobre isso?

Maria Beatriz Luce: O curso de pedagogia é hoje uma licenciatura como as outras, inclusive agora igualadas em carga horária. Não forma o supervisor, o diretor escolar, o inspetor nem o orientador educacional. Essas eram as antigas habilitações da licenciatura e/ou bacharelado em pedagogia, que não existem mais há 10 anos. Hoje trabalhamos com os princípios já instituídos de formação continuada e de gestão democrática, que levam a novas e diversas configurações sobre a organização do trabalho nas escolas e nos órgãos normativos, administrativos e de pesquisa e desenvolvimento dos sistemas educacionais. Então, concebemos as escolas com equipes de coordenação (ou diretivas) compostas por professores e, às vezes, por outros profissionais que também se especializaram em educação, que são reconhecidos por seus pares em experiência e formação continuada, que trabalham colegiadamente, nas secretarias e conselhos municipais e estaduais também. Portanto, as licenciaturas são o ponto de partida, a formação inicial dos profissionais da educação, e não são o lugar da capacitação em funções ou cargos de direção ou especialização.

A licenciatura em pedagogia, como hoje estabelecida, visa atender especificamente à formação de professores para a educação infantil e os anos iniciais do ensino fundamental. Contudo, pela ampla base de fundamentos e noções educacionais que esse curso mantém, dada sua história e perfil de docentes, os licenciados em pedagogia são também reconhecidos por sua condição de coordenação pedagógica. Aliás, penso que um dos maiores desafios que os cursos de pedagogia ainda enfrentam é aprofundar a formação sobre saberes e práticas da docência para crianças. 
Na minha concepção, aderente às diretrizes nacionais atuais, a formação de todos os licenciados deve abranger o domínio dos conhecimentos da matéria que vão trabalhar com as crianças e adolescentes - ou com os jovens e adultos - e de uma base comum nacional de formação docente. Nesta, constam conhecimentos sobre o mundo de hoje, a sociedade em que vivemos, a produção da ciência e da cultura - como em todos os cursos de graduação - e conhecimentos próprios das licenciaturas, a partir da realidade escolar local, nacional e internacional. Todos os licenciandos precisam conhecer as escolas e as condições de vida e de trabalho dos estudantes e dos professores da educação básica; a política educacional e curricular; e os conhecimentos científicos e práticas sobre ensinar e aprender.

Ensinar e aprender acontecem no contexto da realidade escolar e da organização do sistema educacional, portanto, todos os licenciados precisam aprender sobre o direito à educação, a organização do estado brasileiro para a gestão da educação e sobre a organização de uma escola que tenha o trabalho como princípio educativo. O trabalho, nesta perspectiva, deixa de ser uma finalidade da educação básica e passa a ser um princípio para formar pessoas felizes, realizadas, íntegras e críticas, preparadas para a vida em democracia e não apenas para o mercado. Dessa forma, surge a concepção de organização escolar que tem como objeto o conhecimento e, como razão principal, o reconhecimento da individualidade dos sujeitos e da organização da formação coletiva da cidadania. Portanto, organizar práticas democráticas em sala de aula e de gestão da escola com participação, organização e divisão justa do trabalho é um conhecimento e uma prática que todos os licenciados precisam ter, não só os da pedagogia.

Diretores e coordenadores pedagógicos de escolas do ensino fundamental e médio são professores graduados em qualquer das licenciaturas. Quando nós temos essa noção de educação continuada e uma meta do Plano Nacional de Educação, que já foi alcançada em muitos estados brasileiros, de ter 50\% dos professores de educação básica com cursos de pós-graduação, vemos que a formação de coordenador pedagógico e de diretor de escola começa na licenciatura, mas não será específica em curso de graduação. Não existe mais formação de "pedagogo", isto é, de bacharel em pedagogia, desde os pareceres de $2005^{6}$ e $2006 .^{7}$

Essas funções são para quem tem experiência de magistério e pósgraduação, não podem ser para uma pessoa que se forma hoje e já vai ser coordenador ou diretor de uma escola. Para isso temos os cursos

\footnotetext{
6 Parecer CNE/CP no 3/2005. Assunto: Diretrizes curriculares para o curso de pedagogia.

7 Resolução CNE/CP nº 1/2006. Institui as diretrizes curriculares para o curso de graduação em pedagogia, licenciatura.
} 
de especialização, extensão e mestrados profissionais. Defendo que trabalhemos nesse horizonte, porque temos excelentes diretores de escola que são professores de português, de matemática, de sociologia, de artes, de língua estrangeira. Na minha opinião, coordenadores pedagógicos e diretores de escola devem surgir do coletivo da escola, são as pessoas que os colegas reconhecem com qualidade de conhecimento e de liderança.

Maria Beatriz Luce, doutora em Educação pela Michigan State University, é professora titular de Política e Administração da Educação, na Faculdade de Educação da Universidade Federal do Rio Grande do Sul (Porto Alegre, Brasil). Foi membro do Conselho Nacional de Educação (2004-2012); presidente da Comissão de Implantação e reitora pro tempore da Universidade Federal do Pampa (20072011); e secretária de Educação Básica do Ministério da Educação (2014-2015).

lucemb@ufrgs.br

Fernanda Borges de Andrade, mestre pela Universidade de Uberaba (Uniube) e doutoranda em Educação, linha de pesquisa Saberes e Práticas Educativas, na Universidade Federal de Uberlândia (UFU), é professora assistente no Departamento de Educação da Universidade Federal do Triângulo Mineiro (UFTM). De fevereiro de 2011 até junho de 2015 foi coordenadora de Gestão de Processos Educacionais do Pibid da UFTM.

feborgesaz@yahoo.com.br 